\title{
Strain-specific metastatic phenotypes in pheochromocytoma allograft mice
}

\author{
Martin Ullrich1, Josephine Liers',2, Mirko Peitzsch³, Anja Feldmann4, Ralf Bergmann', Ulrich Sommer 5 , \\ Susan Richter2,3, Stefan R Bornstein2,6, Michael Bachmann2,4,7,8, Graeme Eisenhofer2,3,6, Christian G Ziegler6 and \\ Jens Pietzsch ${ }^{1,9}$
}

1Department of Radiopharmaceutical and Chemical Biology, Helmholtz-Zentrum Dresden-Rossendorf, Institute of Radiopharmaceutical Cancer Research, Dresden, Germany

${ }^{2}$ Technische Universität Dresden, School of Medicine, Faculty of Medicine Carl Gustav Carus, Dresden, Germany

${ }^{3}$ Technische Universität Dresden, University Hospital Carl Gustav Carus, Institute of Clinical Chemistry and Laboratory Medicine, Dresden, Germany ${ }^{4}$ Department of Radioimmunology, Helmholtz-Zentrum Dresden-Rossendorf, Institute of Radiopharmaceutical Cancer Research, Dresden, Germany 5Technische Universität Dresden, University Hospital Carl Gustav Carus, Institute of Pathology, Dresden, Germany ${ }^{6}$ Department of Internal Medicine III, Technische Universität Dresden, University Hospital Carl Gustav Carus, Dresden, Germany ${ }^{7}$ Technische Universität Dresden, University Hospital Carl Gustav Carus, Universitäts Krebs Centrum (UCC), Tumorimmunology, Dresden, Germany ${ }^{8}$ Technische Universität Dresden, National Center for Tumor Diseases (NCT), Dresden, Germany

${ }^{9}$ Technische Universität Dresden, School of Science, Faculty of Chemistry and Food Chemistry, Dresden, Germany

Correspondence should be addressed to J Pietzsch: j.pietzsch@hzdr.de

\begin{abstract}
Somatostatin receptor-targeting endoradiotherapy offers potential for treating metastatic pheochromocytomas and paragangliomas, an approach likely to benefit from combination radiosensitization therapy. To provide reliable preclinical in vivo models of metastatic disease, this study characterized the metastatic spread of luciferase-expressing mouse pheochromocytoma (MPC) cells in mouse strains with different immunologic conditions. Bioluminescence imaging showed that, in contrast to subcutaneous non-metastatic engraftment of luciferase-expressing MPC cells in NMRI-nude mice, intravenous cell injection provided only suboptimal metastatic spread in both NMRI-nude mice and hairless SCID (SHO) mice. Treatment of NMRI-nude mice with anti-Asialo GM1 serum enhanced metastatic spread due to substantial depletion of natural killer (NK) cells. However, reproducible metastatic spread was only observed in NK cell-defective SCID/beige mice and in hairless immunocompetent SKH1 mice bearing disseminated or liver metastases, respectively. Liquid chromatography tandem mass spectrometry of urine samples showed that subcutaneous and metastasized tumor models exhibit comparable renal monoamine excretion profiles characterized by increasing urinary dopamine, 3-methoxytyramine, norepinephrine and normetanephrine. Metastases-related epinephrine and metanephrine were only detectable in SCID/beige mice. Positron emission tomography and immunohistochemistry revealed that all metastases maintained somatostatin receptor-specific radiotracer uptake and immunoreactivity, respectively. In conclusion, we demonstrate that intravenous injection of luciferase-expressing MPC cells into SCID/beige and SKH1 mice provides reproducible and clinically relevant spread of catecholamine-producing and somatostatin receptor-positive metastases. These standardized preclinical models allow for precise monitoring of disease progression and should facilitate further investigations on theranostic approaches against metastatic pheochromocytomas and paragangliomas.
\end{abstract}
Key Words
- neuroendocrine tumors
- catecholamines
- bioluminescence imaging
- somatostatin receptors
- small animal positron emission tomography
- metastasis

Endocrine-Related Cancer (2018) 25, 993-1004
(C) 2018 The authors Published by Bioscientifica Ltd. Printed in Great Britain

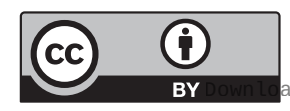

This work is licensed under a Creative Commons Attribution 4.0 International License. 


\section{Introduction}

Adrenal pheochromocytomas and extra adrenal paragangliomas (PPGLs) are rare catecholamineproducing tumors of chromaffin cell origin (Lenders et al. 2005, Harari \& Inabnet 2011, Jemal et al. 2011). In contrast to most other neoplasms, at least 30\% of PPGLs have a hereditary background with variable development of metastatic disease dependent on the mutated gene (Lenders et al. 2005). Germline mutations in succinate dehydrogenase subunit $\mathrm{B}(\mathrm{SDHB})$ are associated with a particularly high penetrance of metastatic disease (Amar et al. 2007). Metastasizing PPGL cells disseminate via lymphatics and blood stream and give rise to solid organ metastases mainly in lymph nodes, bones, lungs and liver (Salmenkivi et al. 2004).

Commonly recommended treatment options for metastatic PPGLs include surgery for removing the tumor bulk, different combinations of chemotherapy, endoradiotherapy using [131I]metaiodobenzylguanidine, external radiation therapy to areas such as bone where metastases are not accessible for surgery, embolization to block tumor blood supply and sometimes also cryoor radiofrequency ablation. However, these treatment options are often considered as palliative (PDQ® Adult Treatment Editorial Board).

Furthermore, somatostatin type 2 receptor (SSTR2)targeting endoradiotherapy offers potential for treating metastatic PPGLs, using e.g. [177Lu]Lu-DOTA-(Tyr $\left.{ }^{3}\right)$ octreotate ([177Lu]Lu-DOTA-TATE) (Ullrich et al. 2016, Kong et al. 2017). Since response rates are usually between 30 and 60\% (Castinetti et al. 2015), this approach is likely to benefit from combination with adjuvant, for example, radiosensitization therapy. Due to the complexity of the metastatic disease, investigations on additional, e.g., adjuvant and radiosensitizing treatments should be performed using preclinical in vivo models reproducibly providing tumors at clinically related metastatic sites.

Currently, no fully differentiated human PPGL cell line model is available for mirroring human disease in mice. An available chromaffin progenitor cell line has been established from a primary human pheochromocytoma but does not produce catecholamines, limiting its utility as a chromaffin cell model (Ghayee et al. 2013). Alternatively, the mouse pheochromocytoma (MPC) cell line deriving from an adrenal tumor of a neurofibromin 1-knockout mouse (Powers et al. 2000) provides an appropriate model for preclinical investigations on metastatic PPGLs in vitro and in vivo (Korpershoek et al. 2012, Ziegler et al. 2013).
From native MPC cells, a subcutaneous tumor model has initially been generated in vivo using NCr-nude mice $\left(\mathrm{NU}(\mathrm{NCr})-F o \times n 1^{n u}\right)$ reproducibly providing non-metastatic allografts (Ohta et al. 2006, 2008). Furthermore, also NMRI-nude mice (Rj:NMRI-Foxn1 ${ }^{n u}$ ) have been successfully employed for generating a standardized subcutaneous tumor model from genetically engineered MPCmCherry cells (Ullrich et al. 2014). This particular model resembles at least in part biochemical features and molecular characteristics of sporadic and hereditary human PPGLs and allows for monitoring tumor progression and treatment response using both in vivo fluorescence imaging and measurement of catecholamines in urine (Ullrich et al. 2016).

The first generation of metastatic pheochromocytoma allograft models was based on intravenous tumor cell injection into immunodeficient NCr-nude mice (NU(NCr)-Foxn1nu) (Ohta et al. 2006, Martiniova et al. 2009, Giubellino et al. 2012). These models provided metastasized allografts occurring predominantly in the liver but only rarely in other organs. It is known that the immunologic phenotype and the general genetic background of mice substantially influence the metastatic spread of circulating tumor cells (Khanna \& Hunter 2005). We therefore hypothesized that intravenous injection of MPC cells into mouse strains featuring different immunologic phenotypes provides allograft models showing a more reproducible pattern of clinically related metastases.

To address the above hypothesis, our objective was to characterize the metastatic spread of luciferase-expressing MPC cells after intravenous injection in mouse strains featuring different immunologic phenotypes and to compare tumor progression, catecholamine excretion and SSTR2 status of different metastases models with a previously established subcutaneous reference model (NMRI-nude mice) (Ullrich et al. 2014, 2016). For non-invasive detection of organ metastases in murine pheochromocytoma models, MRI and bioluminescence imaging (BLI) provide appropriate sensitivity in vivo (Martiniova et al. 2011, Giubellino et al. 2012). To quantify MPC tumor burden, measurement of urinary monoamines provides comparable sensitivity to preclinical imaging as has been demonstrated by us in a subcutaneous allograft model (Ullrich et al. 2014). In the same model, positron emission tomography (PET) using radiolabeled somatostatin analogs allowed for functional imaging of SSTR2 (Ullrich et al. 2016).

Using the aforementioned tools, two mouse strains (SCID/beige and SKH1) were identified providing a highly reproducible and clinically relevant pattern of 
metastasized allografts that can be precisely monitored. These models should facilitate preclinical investigations on theranostic approaches against metastatic PPGLs and help to further understand biological features of these tumors.

\section{Materials and methods}

\section{Cell culture and luciferase gene transfer}

Mouse pheochromocytoma cells (MPCs clone 4/30PRR (Powers et al. 2000)) were routinely cultured as described previously (Ullrich et al. 2014). MPC cells (passage 32) were genetically modified using the lentiviral transfer vector p6NST50-luc (Supplementary Fig. 1, see section on supplementary data given at the end of this article) harboring the open reading frame of a firefly luciferase (luc) and a combined expression cassette of enhanced green-fluorescent protein and zeocin resistance (egfp-zeo) (Morgenroth et al. 2007, Stirnnagel et al. 2010, Ho et al. 2012). Genetically modified cells were named MPC LUC/eGFP-ZEO (abbreviated as MPC ${ }^{L U C / G Z}$ ). Selection of genetically modified cells was performed using $100 \mu \mathrm{g} / \mathrm{mL}$ zeocin (Thermo Fisher Scientific). Cultures containing $>90 \%$ of genetically modified cells were used for experiments (Supplementary Fig. 2A and B).

\section{Animal experiment}

Animal experiments were carried out at the HelmholtzZentrum Dresden-Rossendorf according to the guidelines of German Regulations for Animal Welfare and have been approved by the Local Animal Ethics Committee for Animal Experiments (Landesdirektion Dresden, Germany). Female mice, between 10 and 14 weeks old, were housed in a pathogen-free facility. For tumor induction, an injectable suspension containing $2 \times 10^{6}$ MPCLUC/GZ cells in phosphate-buffered saline was prepared. For generation of the subcutaneous reference model a single bolus of $40 \mu \mathrm{L}$ cell suspension was injected into the right shoulder of NMRI-nude mice (Rj:NMRI-Foxn $1^{n u}$, T cell-deficient, hairless; Janvier Labs, Le Genest-Saint-Isle, France; $n=10$ ). For generation of metastases models, a single bolus of $100 \mu \mathrm{L}$ cell suspension was injected intravenously into the tail vein of NMRI-nude mice $(n=10)$, natural killer (NK) cell-depleted NMRI-nude mice ( $n=5)$, SHO mice (Crl:SHO-Prkdcscid $\mathrm{Hr}^{\mathrm{Hr}}$, $\mathrm{T}$ and $\mathrm{B}$ cell-deficient, hairless; Charles River Laboratories; $n=9$ ), SCID/beige mice (CB17.Cg-PrkdcscidLystbg-J/Crl, $\mathrm{T}$ and $\mathrm{B}$ cell-deficient, NK cell-defective, white-haired;
Charles River; $n=9$ ) and SKH1 mice (Crl:SKH1-Elite$H r^{h r}$, immunocompetent, hairless; Charles River; $n=15$ ). Anesthesia was induced and maintained with inhalation of $10 \%(\mathrm{v} / \mathrm{v})$ desflurane (Baxter, Unterschleißheim, Germany) in 30\% (v/v) oxygen air. Animals were killed using $\mathrm{CO}_{2}$ inhalation and cervical dislocation. For histologic examination, tumors and organs were excised and fixed using 4\% (w/v) paraformaldehyde in Dulbecco's phosphate-buffered saline containing $2 \%(\mathrm{w} / \mathrm{v})$ sucrose. Bone samples were decalcified for 3 days in decalcifier soft (Carl Roth, Karlsruhe, Germany).

\section{NK cell-depleting pre-treatment of NMRI-nude mice}

For depletion of NK cells in NMRI-nude mice, animals $(n=5)$ were pre-treated with $30 \mu \mathrm{L}$ of anti-Asialo GM1 serum (Wako Chemicals GmbH, Neuss, Germany) diluted in Dulbecco's phosphate-buffered saline and administered intraperitoneally $24 \mathrm{~h}$ before intravenous tumor cell injection. Treatment was repeated 2, 6, 9, 13 and 16 days after tumor cell injection.

\section{Bioluminescence imaging}

BLI was performed using the In vivo Xtreme system (Bruker, Billerica, MA, USA). D-Luciferin was prepared and administered according to the manufacturer's instructions (Caliper Life Sciences, Hopkinton, MA, USA). Images were analyzed using the MI 7.2 software (Bruker). In vitro, net luminescence intensity (photons $/ \mathrm{s} / \mathrm{mm}^{2}$ ) of serially diluted tumor cells was determined in a 96-well microplate $(n=2)$. In vivo, net luminescence intensities were determined from dynamic image series. Signals from successfully induced subcutaneous tumors in NMRInude mice $(n=10)$ were quantified from sagittal view images. Signals from successfully induced metastases in NMRI-nude $(n=7)$, NK cell-depleted NMRI-nude $(n=5)$, SHO $(n=6)$, SCID/beige $(n=9)$ and SKH1 mice $(n=12)$ were quantified by summating the intensities of ventral and dorsal view images. X-ray images were merged with bioluminescence images using the linear dodge blending mode of Photoshop CS5 (Adobe).

\section{Positron emission tomography}

PET was performed as described previously (Ullrich et al. 2016) using the preclinical nanoSCAN PET/CT scanner (Mediso, Münster, Germany). Tumor-bearing SCID/beige mice $(n=2)$ and SKH1 mice $(n=2)$ received $15 \mathrm{MBq}$ of $\left[{ }^{68} \mathrm{Ga}\right] \mathrm{Ga}-\mathrm{DOTA}-\left(\mathrm{Tyr}^{3}\right)$ octreotide (TOC) or

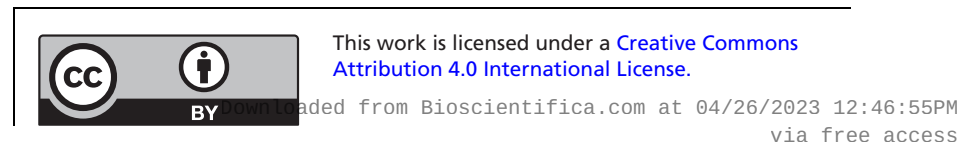


$\left[{ }^{68} \mathrm{Ga}\right] \mathrm{Ga}$-DOTA-(Tyr $\left.{ }^{3}\right)$ octreotate (TATE) at a molar activity of $25 \mathrm{GBq} / \mathrm{\mu mol}$, respectively. Images were merged with $\mathrm{X}$-ray CT.

\section{Determination of free urinary monoamines}

Single-voided urine samples of NMRI-nude mice bearing subcutaneous tumors $(n=10)$, of SCID/beige mice bearing disseminated metastases $(n=9)$ and of SKH1 mice bearing liver metastases $(n=7)$ were collected and urinary concentrations of monoamines were determined simultaneously using liquid chromatography tandem mass spectrometry as described elsewhere (Peitzsch et al. 2013, Ullrich et al. 2014).

\section{SSTR2 immunohistochemistry}

SSTR2 immunohistochemistry was performed on paraformaldehyde-fixed paraffin-embedded tissue samples from SCID/beige mice bearing disseminated metastases $(n=3)$ and from SKH1 mice bearing liver metastases $(n=3)$ using the anti-SSTR2 (UMB1) primary antibody (Abcam) as described previously (Ullrich et al. 2016).

\section{Statistical analysis}

Statistical analysis was performed using Prism, version 5.02 (GraphPad Software). Data are presented as mean \pm standard error of the mean and $n$ represents the number of data sets investigated. Exponential tumor progression curves were fitted from luminescence intensity data using the least squares method weighted by $1 / y^{2}$. Time of tumor formation (when luminescence intensity of tumors exceeded the luminescence intensity of initially injected tumor cells) and tumor growth rates (\% growth per day) were calculated from fitted data. Significance of differences was tested using ANOVA applying Holm-Šídák's post hoc multiple comparison test. Differences were considered significant at $P$ values $<0.05$. Significance of relationships was tested using Pearson's linear correlation test and displayed as Pearson's correlation coefficient $\left(r_{\mathrm{p}}\right)$.

\section{Results}

\section{BLI of MPCLUC/GZ cells in vitro and initial cell distribution in vivo}

Luciferase-expressing mouse pheochromocytoma (MPCLUC/GZ) cells were generated (Supplementary Figs 1,
$2 \mathrm{~A}$ and $\mathrm{B})$ to perform non-invasive detection of tumor formation in mice. In vitro, BLI detected a minimum of 125 tumor cells seeded in a 96-well microplate (Fig. 1A). Correlation analysis showed a significant positive linear relationship $\left(r_{\mathrm{p}}=0.99\right)$ between number and luminescence intensity of tumor cells indicating that BLI allows for precise tumor cell quantification.

As exemplary shown for the NMRI-nude strain, in vivo BLI detected a local accumulation of subcutaneously injected MPC ${ }^{\mathrm{LUC} / \mathrm{GZ}}$ cells restricted to the injection site in the right shoulder (Fig. 1B, reference model). In the same strain, accumulation of intravenously injected MPCLUC/GZ cells was detectable in lungs, liver and spleen (Fig. 1B). A comparable distribution of intravenously injected MPCLUC/GZ cells was also observed in NK cell-depleted NMRI-nude, SHO, SCID/beige and SKH1 mice with slightly different dynamics (Supplementary Fig. 3A and B).

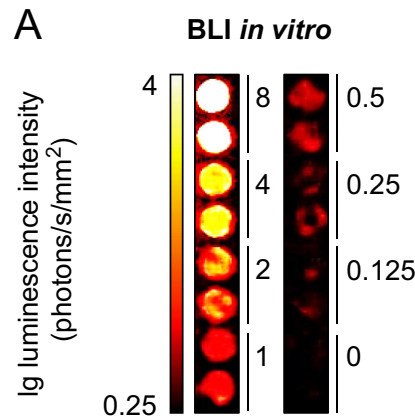

cell number $\times 10^{3}$

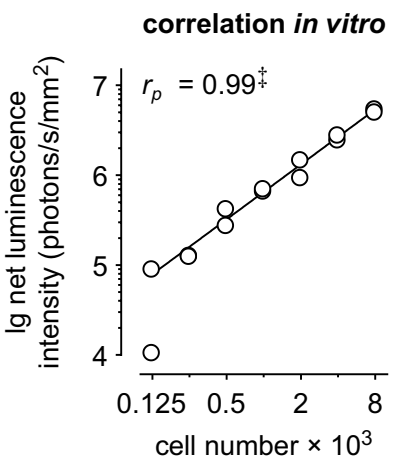

cell number $\times 10^{3}$

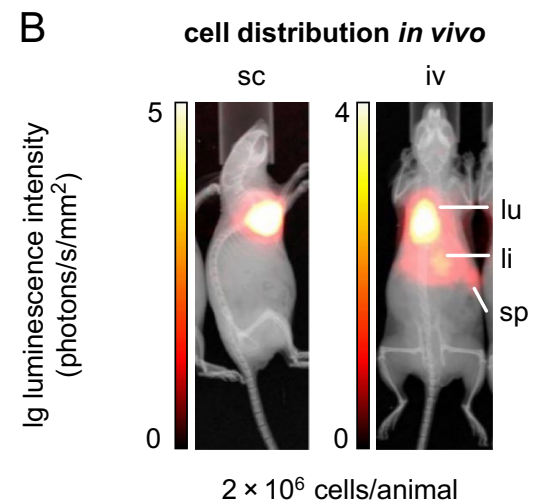

Figure 1

BLI of MPCLUC/Gz cells in vitro and in vivo; (A) imaging sensitivity and correlation between number and luminescence intensity of serially diluted MPCLUC/GZ cells in a 96-well microplate; $n=2$; significance of relationship: ${ }^{*} P<0.001$; (B) distribution of MPCLUC/GZ cells in NMRI-nude mice 20 min after subcutaneous vs intravenous injection; (iv) intravenous, (li) liver, (lu) lung, (sc) subcutaneous, (sp) spleen. A full colour version of this figure is available at https://doi.org/10.1530/ERC-18-0136. 


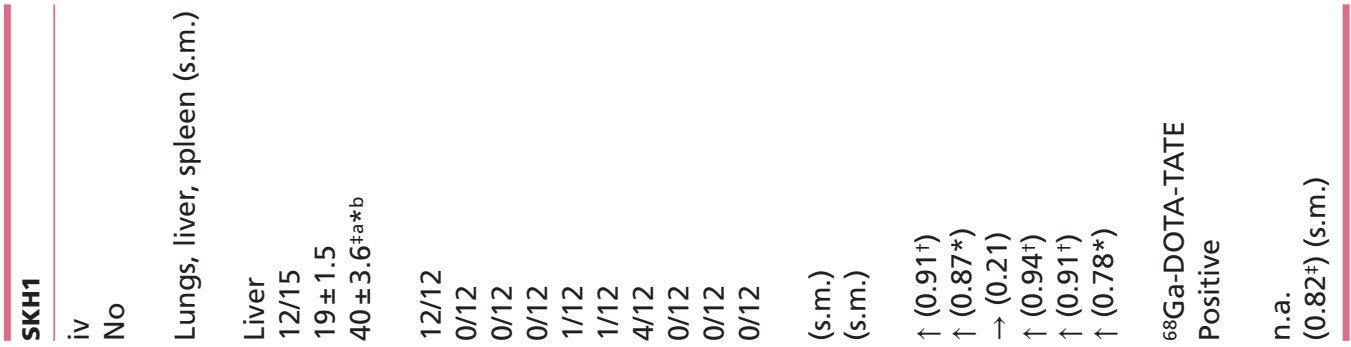

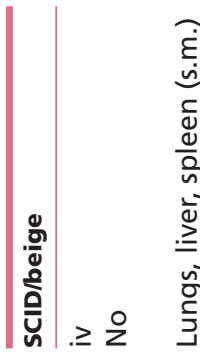

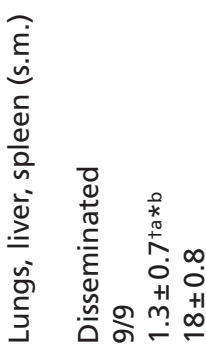<smiles>CO</smiles>

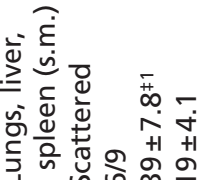

ํํำำำํำํำำ

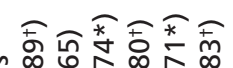

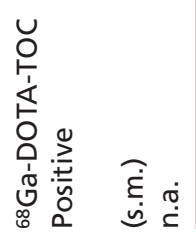

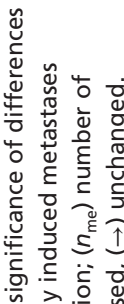

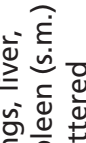

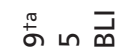

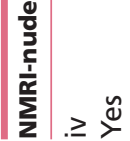

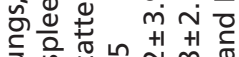

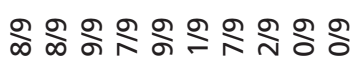

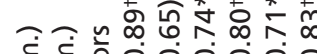

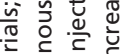

T⿱艹

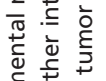

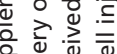

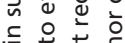

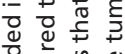

כ)

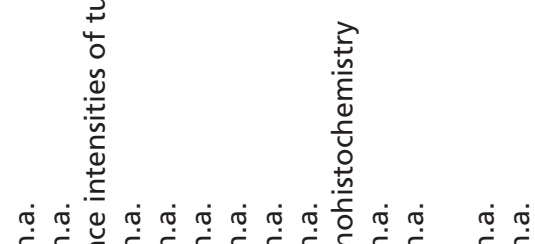

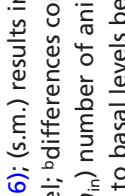
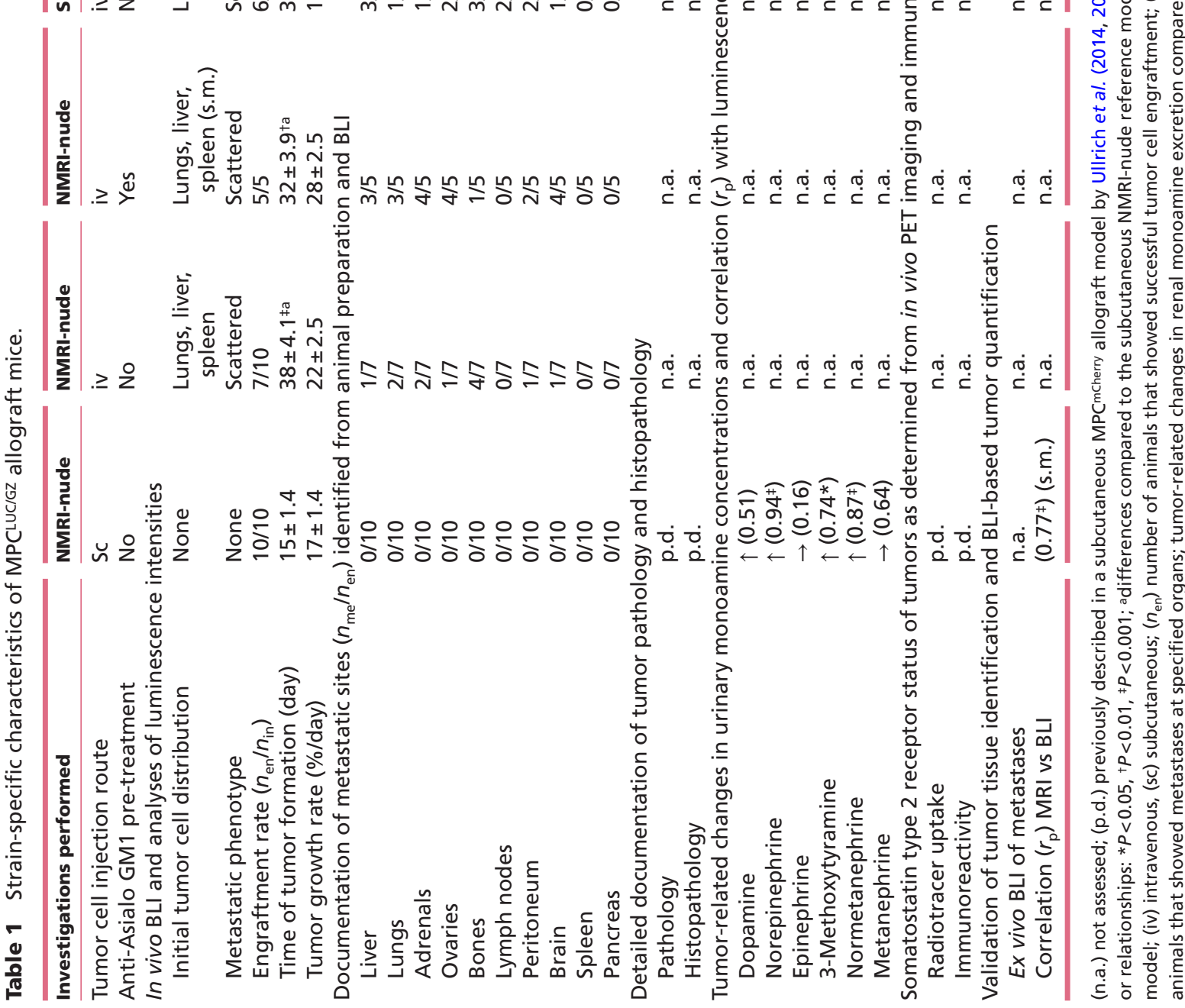

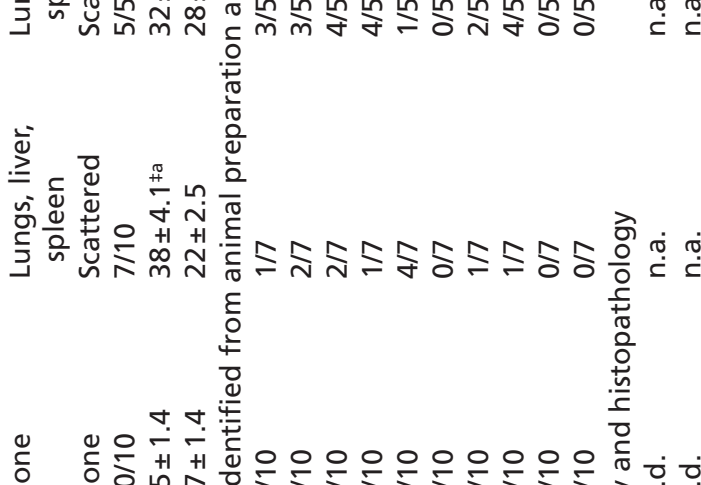

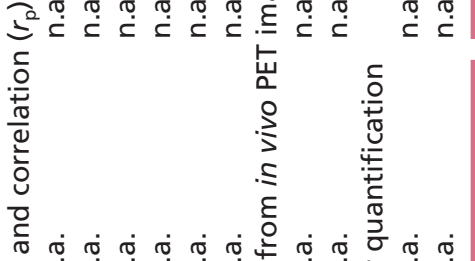

,
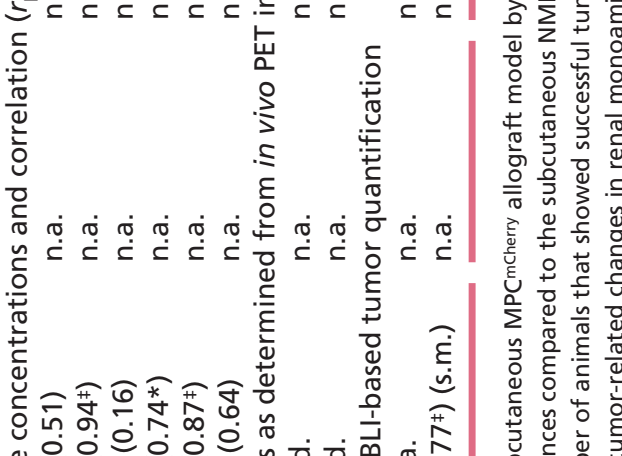

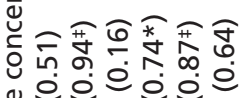

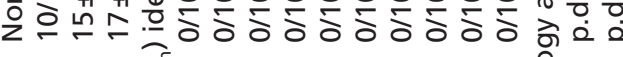




\section{Engraftment of MPCLUC/Gz cells and metastatic} spread in different mouse strains

Subcutaneous injection of $\mathrm{MPC}{ }^{\mathrm{LUC} / \mathrm{GZ}}$ cells into our reference model, NMRI-nude mice, resulted in an engraftment rate of $100 \%$. Intravenous tumor cell injection resulted in engraftment rates of $70 \%$ in NMRI-nude mice, $100 \%$ in NK cell-depleted NMRI-nude mice, 67\% in SHO mice, 100\% in SCID/beige mice and $80 \%$ in SKH1 mice (Table 1).

In vivo, BLI of MPCLUC/GZ allografts (Fig. 2A) showed that subcutaneous cell injection into NMRI-nude mice induced ectopic non-metastasizing tumors. Intravenous cell injection was associated with a non-consistent pattern of sporadically scattered metastases in untreated NMRI-nude mice, NK cell-depleted NMRI-nude mice and SHO mice. In contrast, intravenous tumor cell injection into SCID/beige mice provided a consistent pattern of multifocal disseminated metastases in liver, adrenal glands, bones, lungs, ovaries, and, rarely, also in brain and attached to the peritoneum (Supplementary Figs 4A, B, C, D, E, F, G, H, 5A, B, C, D, E, F, G, H, I and $6 \mathrm{~A}, \mathrm{~B}, \mathrm{C}, \mathrm{D}, \mathrm{E}, \mathrm{F})$. Furthermore, intravenous tumor cell injection into SKH1 mice predominantly induced multifocal liver metastases (Supplementary Fig. 7A, B and C).

\section{Progression of metastasized MPCLUC/GZ allografts in different mouse strains}

Correlation analyses (Supplementary Fig. 8A, B, C and D) showed a significant positive linear relationship between tumor volume as determined using MRI (Supplementary information for methodologic details and discussion) and luminescence intensity of subcutaneous MPC ${ }^{\mathrm{LUC} / \mathrm{GZ}}$ tumors in NMRI-nude mice $\left(r_{\mathrm{p}}=0.77\right)$ as well as between tumor volume and luminescence intensity of liver metastases in SKH1 mice $\left(r_{\mathrm{p}}=0.82\right)$. These results indicate that BLI allows for semi-quantitative in vivo monitoring of MPC $\mathrm{MUC}^{\mathrm{LUZ}}$ cellderived subcutaneous tumors and metastases in mice with comparable accuracy.

Monitoring the luminescence intensities of progressing MPC ${ }^{\mathrm{LUC} / \mathrm{GZ}}$ allografts in vivo (Fig. 2B) showed that tumor formation (time when luminescence intensity of tumors exceeded the luminescence intensity of initially injected tumor cells) occurred 15 days after subcutaneous cell injection in NMRI-nude mice. After intravenous cell injection, formation of metastases was significantly delayed, requiring 38 days in untreated NMRI-nude mice, 32 days in NK cell-depleted NMRI-nude mice and 39 days in SHO mice. In contrast, formation of disseminated metastases already occurred 1.3 days after intravenous cell injection in SCID/beige mice even

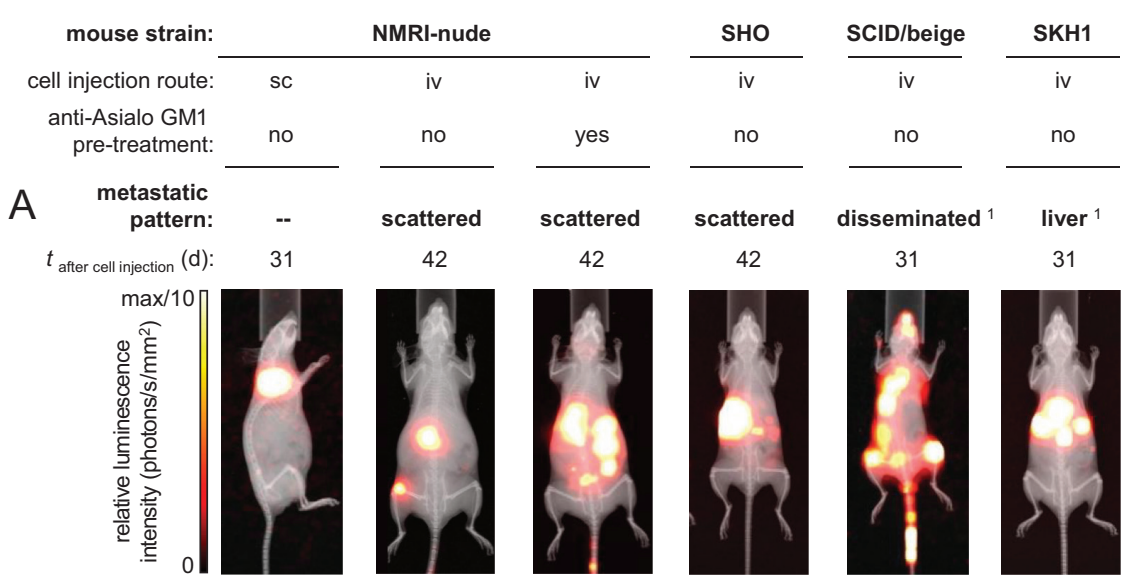

B
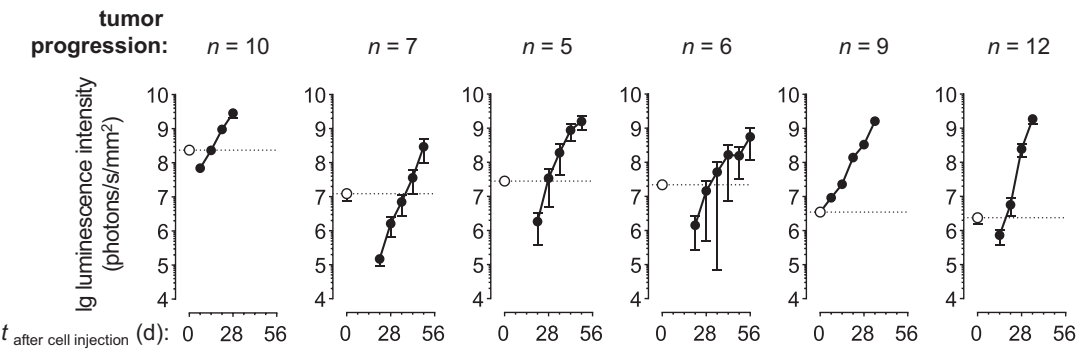

Figure 2

BLI of subcutaneous and metastasized MPCLUC/GZ allografts in mice featuring different immunologic phenotypes; (A) metastatic spread at defined time points after cell injection; of note, images were individually scaled to $1 / 10$ of the maximal luminescence intensity to also visualize small lesions, therefore, signal dimensions do not represent tumor size; (B) progression of luminescence intensities of subcutaneous tumors and metastases in vivo; logarithmic scaling of $y$-axis; (white data points, dotted lines) luminescence intensity of initially distributed tumor cells detected $32 \mathrm{~min}$ after subcutaneous and $20 \mathrm{~min}$ after intravenous cell injection (black data points, continuous lines) luminescence intensities of progressing tumors; depletion of natural killer (NK) cells resulted from treatment with anti-Asialo GM1 serum; the meaning of scattered metastases and disseminated metastases is given in the results section; (iv) intravenous, (sc) subcutaneous; 'animal models showing reproducible pattern of metastases. A full colour version of this figure is available at https://doi.org/10.1530/ERC-18-0136. 
though these particular bioluminescence signals were most likely emitted from surviving tumor cells along the tail vein injection route. Liver metastases in SKH1 mice were detected 19 days after intravenous cell injection and showed a significantly higher exponential growth rate (40\%/day) compared to the other metastases models (between 17 and 27\%/day).

Initial BLI measurements showed that after intravenous MPCLUC/GZ cell injection, NMRI-nude, NK cell-depleted NMRI-nude and SHO mice did not meet the requirements for reproducible induction of metastases. Therefore, further characterization of metastatic phenotypes was only carried out in SCID/beige and SKH1 mice and pathophysiology was compared to the subcutaneous NMRI-nude reference model.

\section{Renal monoamine excretion related to subcutaneous vs metastasized MPCLUC/Gz allografts}

Measurement of urinary catecholamines and their respective $\mathrm{O}$-methylated metabolites (Fig. 3A) revealed that subcutaneous $\mathrm{MPC}^{\mathrm{LUC} / \mathrm{GZ}}$ tumors in NMRI-nude mice, disseminated metastases in SCID/beige mice and liver metastases in SKH1 mice, were all associated with comparable changes in renal monoamine excretion profiles characterized by increasing concentrations of dopamine, norepinephrine, 3-methoxytyramine and normetanephrine. In SCID/beige mice, a significantly lower basal monoamine excretion exceptionally allowed for additional detection of small changes in metastasesrelated urinary epinephrine and metanephrine.

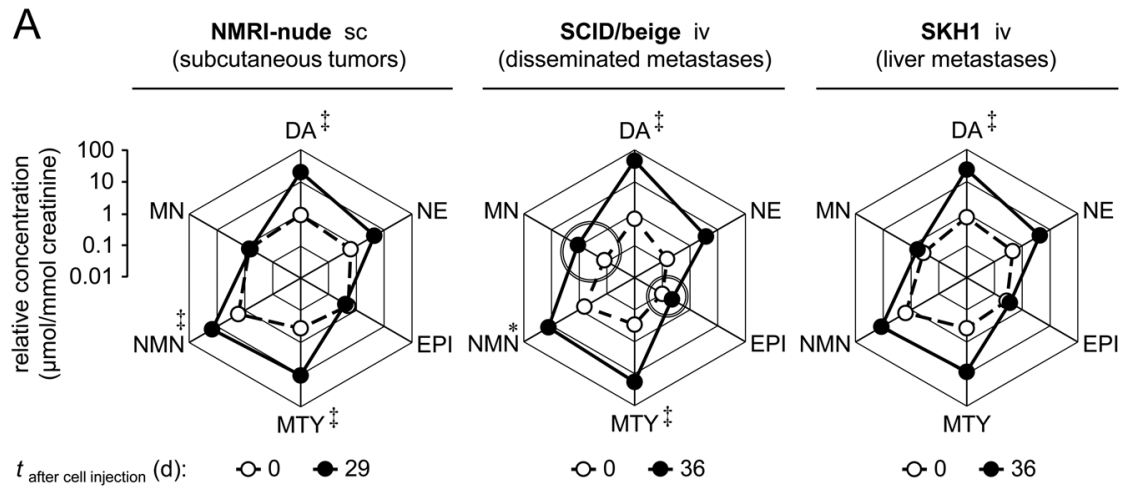

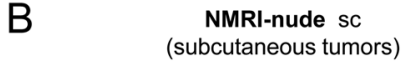

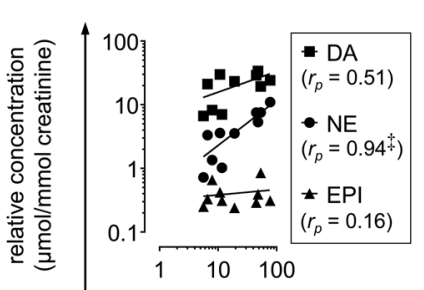

luminescence intensity of tumors (photons $/ \mathrm{s} / \mathrm{mm}^{2}$ ) $\times 10^{8}$
C

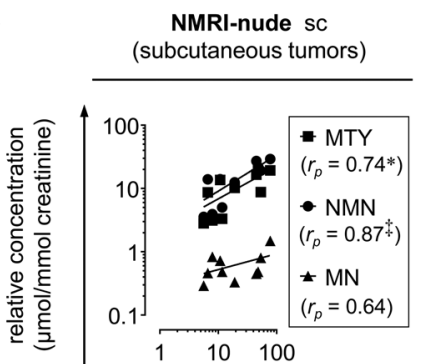

SCID/beige iv (disseminated metastases)

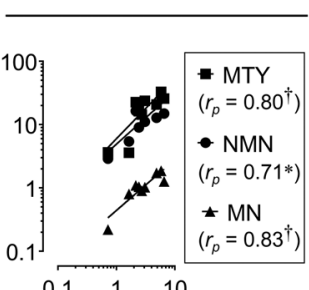

luminescence intensity of tumors (photons $/ \mathrm{s} / \mathrm{mm}^{2}$ ) $\times 10^{8}$
SKH1 iv (liver metastases)

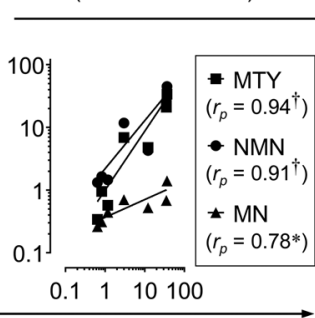

SKH1 iv (liver metastases)

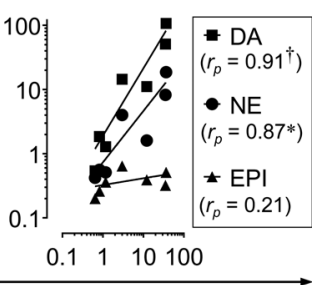

Figure 3

Renal monoamine excretion of subcutaneous and metastasized MPCLUC/GZ allograft models;

(A) pathophysiologic changes in monoamine excretion profiles related to subcutaneous tumors in NMRI-nude mice, disseminated metastases in $\mathrm{SCID} /$ beige mice and liver metastases in SKH1 mice; (white data points, dashed line) physiologic excretion profile before tumor cell injection; (black data points, continuous line) excretion profile after a defined time of tumor growth; double-lined circles mark increasing urinary concentrations of epinephrine and metanephrine detectable in SCID/beige mice; (B and C) correlation between luminescence intensity of stumors and urinary concentrations of free catecholamines and $O$-methylated catecholamine metabolites; logarithmic scaling of $x$ - and $y$-axes; significance of differences or relationships: ${ }^{*} P<0.05,{ }^{\ddagger} P<0.001$; (DA) dopamine, (EPI) epinephrine, (MN) metanephrine, (MTY) 3-methoxytyramine, (NE) norepinephrine, (NMN) normetanephrine, (iv) intravenous, (sc) subcutaneous. http://erc.endocrinology-journals.org https://doi.org/10.1530/ERC-18-0136
() 2018 The authors Published by Bioscientifica Ltd. Printed in Great Britain
This work is licensed under a Creative Commons Attribution 4.0 International License. 
Correlation analyses (Fig. 3A, B and C) showed significant linear relationships between luminescence intensities of MPC ${ }^{\mathrm{LUC} / \mathrm{GZ}}$ tumors and urinary concentrations of three urinary monoamines in the subcutaneous NMRI-nude reference model (norepinephrine, 3-methoxytyramine, normetanephrine), compared to five urinary monoamines in the disseminated SCID/beige metastases model (dopamine, epinephrine, 3-methoxytyramine, normetanephrine, metanephrine) and five urinary monoamines in the SKH1 liver metastases model (dopamine, norepinephrine, 3-methoxytyramine, metanephrine, epinephrine). Of note, significant linear relationships with luminescence intensities of tumors were more frequently observed among $O$-methylated catecholamine metabolites compared to free catecholamines. These results indicate that measurement of urinary monoamines allows for non-invasive and precise quantification of metastasized MPC ${ }^{\mathrm{LUC} / \mathrm{GZ}}$ allografts in mice.

\section{Somatostatin type 2 receptors in metastasized MPCLUC/GZ allografts}

PET showed specific uptake of the somatostatin type 2 receptor (SSTR2)-targeting radiotracer $\left[{ }^{68} \mathrm{Ga}\right] \mathrm{Ga}-\mathrm{DOTA}-\mathrm{TOC}$ in MPCLUC/GZ metastases in bone, lung, liver and ovaries of SCID/beige mice (Fig. 4A). A second radiotracer $\left[{ }^{68} \mathrm{Ga}\right] \mathrm{Ga}$-DOTA-TATE, which exhibits comparable SSTR 2 specificity to $\left[{ }^{68} \mathrm{Ga}\right.$ ] Ga-DOTA-TOC, was specifically taken up by liver metastases in SKH1 mice (Fig. 4B).

Immunohistochemistry on metastasized MPCLUC/GZ allografts from SCID/beige and SKH1 mice confirmed elevated SSTR2 levels in metastases compared to surrounding healthy tissue (Fig. 5A, B, C, D, E, F, G, H, $\mathrm{I}$ and J). These results indicate that SSTR2 is maintained in metastasized MPCLUC/GZ allografts, irrespective of metastatic site or mouse strain, emphasizing its utility as a molecular theranostic target.

\section{Discussion}

The present study characterized mouse strain-specific metastatic phenotypes of intravenously induced luciferase-expressing MPCLUC/GZ allografts, in particular with regard to metastatic spread, tumor progression, catecholamine excretion and somatostatin type 2 (SSTR2) receptor status. The investigated mouse strains SKH1, NMRI-nude, SHO and SCID/beige were preselected with regard to increasing severity of genetically
A
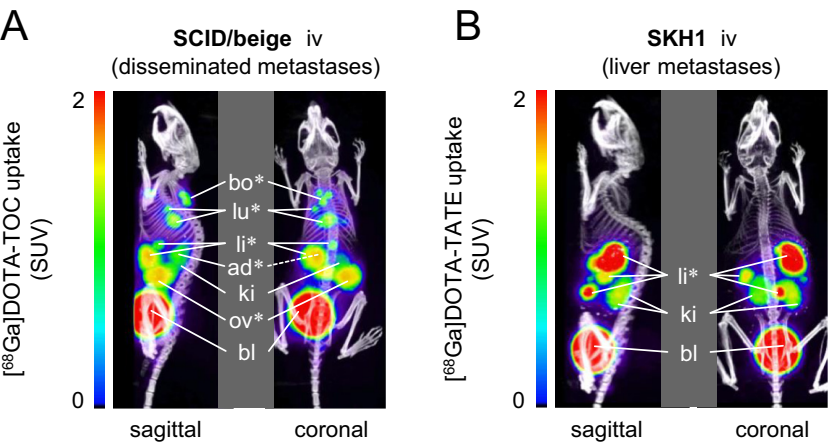

Figure 4

PET imaging of SSTR2 in two metastasized MPCLUCIGZ allograft models; positron emission tomograms merged with X-ray computed tomograms as anatomic references; maximum intensity projections $90 \mathrm{~min}$ after radiotracer injection; (A) [68Ga]Ga-DOTA-TOC uptake of disseminated metastases in SCID/beige mice; (B) [ ${ }^{68} \mathrm{Ga}$ ]Ga-DOTA-TATE uptake of liver metastases in SKH1 mice; (*) metastatic sites; (ad) adrenal gland; (bl) bladder; (bo) bone, scapula; (ki) kidneys; (li) liver; (lu) lung; (ov) ovary; (SUV) standardized uptake value. A full colour version of this figure is available at https://doi.org/10.1530/ERC-18-0136.

related immune cell defects according to manufacturer's specifications and due to a hairless or white-haired phenotype for better optical imaging of organ metastases (for details see 'Materials and methods' section). In particular, intravenous injection of MPC ${ }^{L U C / G Z}$ cells into SCID/beige and SKH1 mice resulted in highly reproducible and clinically relevant pattern of catecholamineproducing and SSTR2-positive metastases. These models allow for monitoring the progression of metastases precisely by two methods, in vivo BLI and measurement of tumor-related urinary monoamines.

In a previous study, we investigated the efficiency of radiolabeled DOTA-(Tyr $\left.{ }^{3}\right)$ octreotate for SSTR2targeted imaging ([64 $\mathrm{Cu}] \mathrm{Cu}$-DOTA-TATE) and treatment ([177Lu]Lu-DOTA-TATE) of metastatic PPGLs in a subcutaneous MPC-mCherry allograft model using NMRI-nude mice (Ullrich et al. 2016). For this particular radiopharmacologic investigation, the subcutaneous tumor model had the advantage that the location of one single lesion was known and its size and morphology could easily be measured allowing for precise determination of radiotracer uptake and treatment response.

Nevertheless, subcutaneous MPC allografts do not entirely resemble the microenvironment at clinically relevant target organs of PPGL metastasis such as lymph nodes, bones, lungs and liver (Salmenkivi et al. 2004). In terms of modeling metastases in vivo, injection of tumor cells into the blood circulation of mice is a common approach. The difficulty thereafter is to monitor disease progression. For this purpose, the genetically modified luciferase-expressing MPC ${ }^{\mathrm{LUC} / \mathrm{GZ}}$ cell line was generated

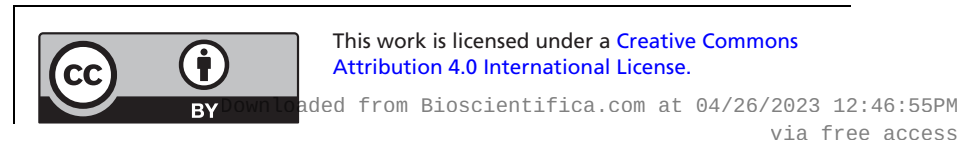


SCID/beige iv (disseminated metastases)

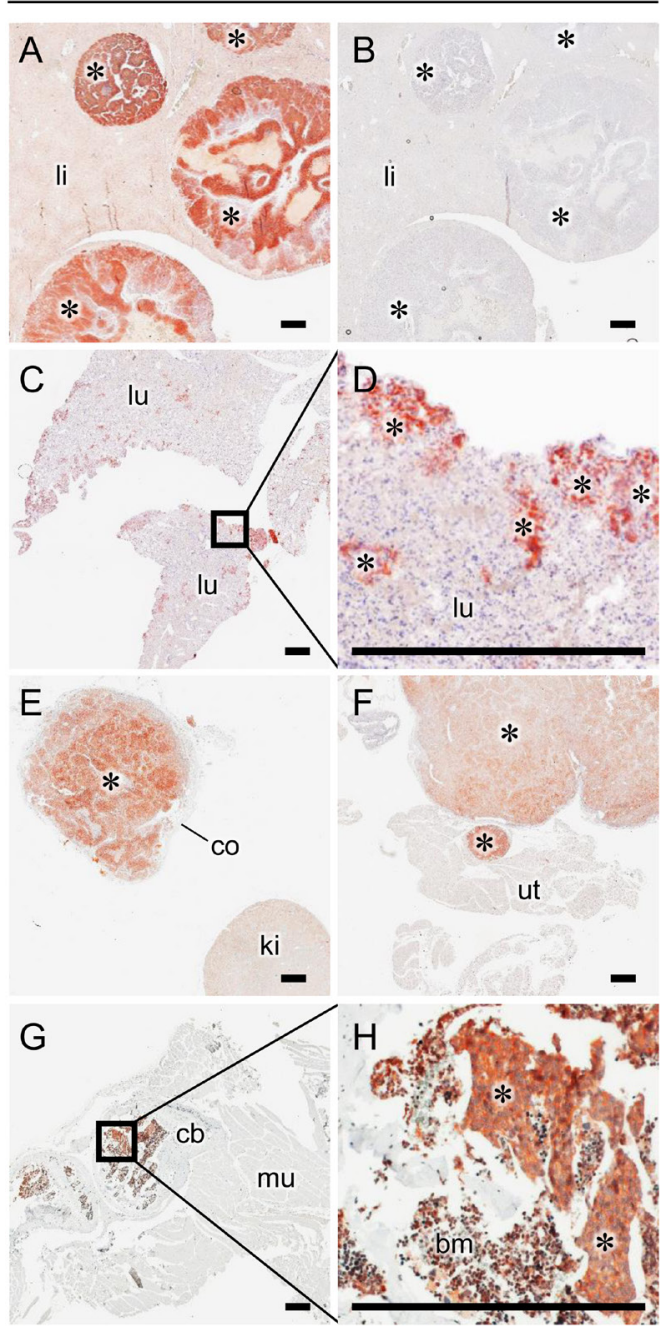

SKH1 iv (liver metastases)

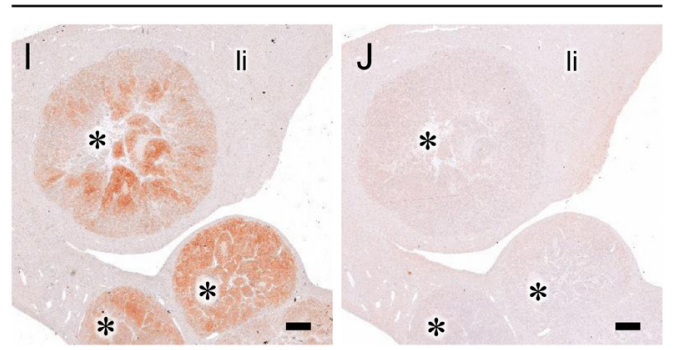

Figure 5

SSTR2 immunohistochemistry of metastasized MPCLUC/GZ allografts in SCID/beige and SKH1 mice: (A, I) liver metastases showing initial necrosis; $(B, J)$ IgG isotype control stain of liver metastases; (C, D) small scattered metastases from periphery of lung tissue; $(E)$ adrenal metastasis surrounded by adrenocortical tissue; (F) ovarian metastasis connected to uterine tissue; $(\mathrm{G}, \mathrm{H})$ nests of bone metastases surrounded by bone marrow; $(*)$ metastasized allografts; (bm) bone marrow; (cb) cortical bone; (co) adrenocortical tissue; (iv) intravenous, (ki) kidney; (li) liver tissue; (lu) lung tissue; (mu) muscle tissue; (sc) subcutaneous; (ut) uterine tissue; scale bar: $0.5 \mathrm{~mm}$. A full colour version of this figure is available at https://doi. org/10.1530/ERC-18-0136. allowing for in vivo BLI of metastasized allografts after intravenous injection into a tail vein.

Using the intravenous cell injection route, it has to be considered that formation of metastasized allografts arising from circulating MPC ${ }^{\mathrm{LUC} / \mathrm{GZ}}$ cells does not depend on vascular invasion, pre-metastatic selection and epithelial-mesenchymal transition usually occurring in metastasizing primary tumors (Labelle \& Hynes 2012, Daphu et al. 2013). Thus, these early metastatic events cannot be investigated in intravenously induced MPCLUC/GZ metastases models. Formation of metastases in these models primarily depends on later metastatic events such as dissemination of MPCLUC/GZ cells via lymph system or blood circulation, extravasation and interactions of tumor cells with blood components and target tissues.

This study demonstrates that metastatic phenotypes of intravenously induced MPC LUC/GZ allograft models strongly depend on genetic background and immunologic condition of the mouse stain. After intravenous injection, MPC $^{\text {LUC/GZ }}$ cells did not circulate long, with the majority accumulating rapidly in lungs and smaller fractions in liver and spleen. In contrast to this initial cell distribution, in particular lungs later showed a much lower metastatic burden compared to liver; spleen remained free from metastases. Our results indicate that the engraftment of circulating MPCLUC/GZ cells in murine organs essentially depends on the tissue-specific microenvironment rather than on the number of entrapped cells.

NMRI-nude mice carrying a homozygous Foxn $1^{n u}$ mutation are frequently used for generating tumor allograft or xenograft models. These mice lack a thymus and are therefore $T$ cell deficient allowing for the engraftment of tumor cells or tumor tissue without activation of adaptive immune responses. Since NMRI-nude mice have been successfully employed for generating a standardized subcutaneous tumor model from genetically engineered MPCmCherry cells (Ullrich et al. 2014, 2016), we consequently investigated whether this particular strain would also allow for generating a standardized metastases model after intravenous injection of MPCLUC/GZ cells. Under the investigated conditions, only subcutaneous cell injection allowed for reproducible engraftment of MPCLUC/GZ cells in NMRI-nude mice, whereas intravenous cell injection led to inefficient engraftment and nonreproducible metastatic scatter. Since combined $\mathrm{T}$ and B cell deficiency in SHO mice carrying a homozygous Prkdcsid mutation did not improve the engraftment of circulating MPC ${ }^{L U C / G Z}$ cells, we suspect innate immune responses to be responsible. 
NK cells are essential effectors in the response to tumor formation. Consistent with previous reports showing that the genetic background of NMRI-nude and SHO mice is associated with high NK cell numbers (Dorshkind et al. 1985, Budzynski \& Radzikowski 1994), both strains not only showed suboptimal engraftment of circulating MPCLUC/GZ cells, but also the longest delay in tumor formation. In support of our hypothesis, in vivo depletion of NK cells selectively performed in NMRI-nude mice using anti-Asialo GM1 serum facilitated the engraftment of circulating MPCLUC/GZ cells and preponed tumor formation; however, number and activity of NK cells were not determined in these mice. Additional interactions of anti-Asialo GM1 serum with murine monocytes, fetal thymocytes and basophils might have also contributed (Habu et al. 1981, Kasai et al. 1981, Nishikado et al. 2011).

In SCID/beige mice, impaired NK cell function due to the Lyst ${ }^{b-J}$ mutation in addition to $\mathrm{T}$ and B cell deficiency (MacDougall et al. 1990) was associated with highly efficient engraftment of circulating MPC ${ }^{\mathrm{LUC} / \mathrm{GZ}}$ cells and almost immediate tumor formation. These findings indicate that NK cells are substantially involved in the innate immune response against circulating MPCLUC/GZ cells. Thus, it appears that well-directed NK cell response against circulating tumor cells may allow for protective treatment against metastasizing PPGL cells.

The highly reproducible pattern of disseminated MPCLUC/GZ metastases in SCID/beige mice provides an opportunity for studying metastasis to the bone, one of the most frequent target organs of metastatic PPGLs in patients. Furthermore, MPCLUC/GZ metastases occurring in the adrenal glands of SCID/beige mice morphologically resemble orthotopic tumors, potentially enabling studies on primary pheochromocytomas, too.

SKH1 mice are capable of generating both innate and adaptive immune responses against circulating MPCLUC/GZ cells. Interestingly, only liver tissue of SKH1 mice provided an adequate hosting microenvironment for successful engraftment of MPCLUC/GZ cells presumably due to organspecific immunologic tolerance or further unknown processes. Most importantly, MPC ${ }^{\mathrm{LUC} / \mathrm{GZ}}$ liver metastases in SKH1 mice prospectively allow for therapeutic investigations in the presence of an entirely functional immune system.

For BLI of metastasized pheochromocytoma allografts in mice, other genetically modified luciferase-expressing cell lines such as MPC-GL9 (Powers et al. 2014) and mouse tumor tissue (MTT)-luc (Giubellino et al. 2012) have been generated previously. However, MPC-GL9 cells lack an antibiotic resistance for selection in vitro and
MTT-luc cell-derived tumors have shown uncommonly high aggressiveness in vivo. In contrast, zeocin resistance of the MPCLUC/GZ cell line allowed for efficient selection of genetically modified clones in vitro. Moreover, MPCLUC/GZ cell-derived metastases in mice progressed with reasonable aggressiveness and therefore provide an appropriate time frame for therapeutic testing.

The present study demonstrates that measurement of renal monoamine excretion in SCID/beige and SKH1 mice, in particular of dopamine, 3-methoxytyramine and normetanephrine, allows for most precise non-invasive quantification of metastasized MPCLUC/GZ allografts. Thus, this preclinical diagnostic approach follows clinical procedures based on measurements of metanephrines in plasma and urine for detecting PPGLs (Lenders \& Eisenhofer 2017).

Although MPC cells are known to express phenylethanolamine $\mathrm{N}$-methyltransferase (PNMT), the key enzyme of epinephrine synthesis (Powers et al. 2000), considerable increases particularly in urinary epinephrine and its $O$-methylated metabolite metanephrine were only detectable in SCID/beige mice bearing disseminated MPCLUC/GZ metastases. The prevalent appearance of adrenal metastases in SCID/beige mice may explain these observations since adrenal cortical steroids are known to induce PNMT in primary pheochromocytomas (Eisenhofer et al. 2011). Furthermore, a low basal monoamine excretion and a high metastatic burden in SCID/beige mice may also have facilitated the detection of tumor-related epinephrine and metanephrine in urine. Taken together, measurement of tumor-related monoamines in urine provides a reliable alternative to small animal imaging approaches in terms of monitoring the overall burden of metastasized MPC ${ }^{\text {LUC/GZ }}$ allografts in mice.

PET and immunohistochemistry showed that SSTR2 is a molecular theranostic target also in metastasized MPCLUC/GZ allografts, irrespective of metastatic site or mouse strain. These findings are in agreement with clinical findings of high SSTR2 densities in metastatic human PPGLs, especially in those due to mutations in succinate dehydrogenase subunit 2 (SDHB) (Elston et al. 2015, Janssen et al. 2015, Tan et al. 2015). Thus, metastasized

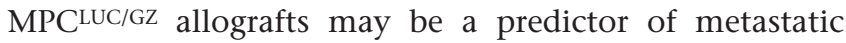
lesion responses to SSTR2-targeting treatments.

Inconclusion, thisstudy demonstrates that intravenous injection of MPC ${ }^{\mathrm{LUC} / \mathrm{GZ}}$ cells into SCID/beige and SKH1 mice provides reproducible and clinically relevant pattern of catecholamine-producing and SSTR2-positive metastases. These preclinical models allow for monitoring

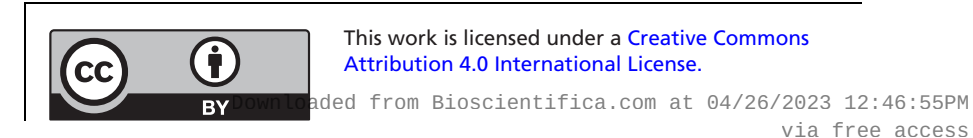


disease progression precisely using BLI and measurements of tumor-related urinary monoamines. Prospectively, MPCLUC/GZ metastases models will facilitate investigations on therapeutic approaches against metastatic PPGLs based on combinations of SSTR2-targeted endoradiotherapy with adjuvant and radiosensitizing drugs, for example, cyclooxygenase 2-selective inhibitors (Laube et al. 2016).

\section{Supplementary data}

This is linked to the online version of the paper at https://doi.org/10.1530/ ERC-18-0136.

\section{Declaration of interest}

The authors have declared that no competing interest exists. The funding sponsors had no role in the design of the study; in the collection, analyses, or interpretation of data; in the writing of the manuscript or in the decision to publish the results.

\section{Funding}

This work was supported by the Deutsche Forschungsgemeinschaft (DFG) grants BE-2607/1-2 (R B and J P), ZI-1362/2-2 (C G Z and G E), the Collaborative Research Center Transregio 205 'The Adrenal: Central Relay in Health and Disease' (CRC/TRR 205/1; M U, M P, S R, S R B, G E, C G Z, and $J$ P) and the Paradifference Foundation (Consortium for Personalized Targeted Therapy for SDHB-mutated Metastatic PPGLs).

\section{Author contribution statement}

$M U$ and $J P$ jointly conceived and supervised the study. $M U, J L$ and $R$ $B$ performed experiments and analyzed data. M $P$ performed liquid chromatography tandem mass spectrometry analyses. A F and M B installed the luciferase reporter gene in MPC cells. U S contributed histopathologic examinations. S R and C G Z contributed cell analyses. M B, G E and J P provided analytical tools and supported the supply of reagents. $S R B$, G E and M B gave conceptual and editorial advice. M U, C G Z and J P interpreted data and wrote the paper. All authors discussed results and implications and commented on the manuscript at all stages. All authors read the paper and contributed to its final form.

\section{Acknowledgments}

The authors greatly acknowledge the excellent technical assistance of Andrea Suhr, Sonja Lehnert, Regina Herrlich and Sebastian Meister (all Department of Radiopharmaceutical and Chemical Biology Institute of Radiopharmaceutical Cancer Research, Helmholtz-Zentrum DresdenRossendorf). The authors further thank Silke Zeugner for coordinating histopathologic evaluations at the Institute of Pathology, University Hospital Carl Gustav Carus, Technische Universität Dresden. MPC 4/30PRR cells were kindly provided by Prof. Arthur Tischler, Dr James Powers and Prof. Karel Pacak. C G Z and J P shared senior authorship.

\section{References}

Amar L, Baudin E, Burnichon N, Peyrard S, Silvera S, Bertherat J, Bertagna X, Schlumberger M, Jeunemaitre X, Gimenez-Roqueplo AP, et al. 2007 Succinate dehydrogenase B gene mutations predict survival in patients with malignant pheochromocytomas or paragangliomas. Journal of Clinical Endocrinology and Metabolism 92 3822-3828. (https://doi.org/10.1210/jc.2007-0709)

Budzynski W \& Radzikowski C 1994 Cytotoxic cells in immunodeficient athymic mice. Immunopharmacology and Immunotoxicology 16 319-346. (https://doi.org/10.3109/08923979409007097)

Castinetti F, Kroiss A, Kumar R, Pacak K \& Taieb D 201515 YEARS OF PARAGANGLIOMA: imaging and imaging-based treatment of pheochromocytoma and paraganglioma. Endocrine-Related Cancer 22 T135-T145. (https://doi.org/10.1530/ERC-15-0175)

Daphu I, Sundstrom T, Horn S, Huszthy PC, Niclou SP, Sakariassen PO, Immervoll H, Miletic H, Bjerkvig R \& Thorsen F 2013 In vivo animal models for studying brain metastasis: value and limitations. Clinical and Experimental Metastasis 30 695-710. (https://doi.org/10.1007/ s10585-013-9566-9)

Dorshkind K, Pollack SB, Bosma MJ \& Phillips RA 1985 Natural killer (NK) cells are present in mice with severe combined immunodeficiency (scid). Journal of Immunology 134 3798-3801.

Eisenhofer G, Pacak K, Huynh TT, Qin N, Bratslavsky G, Linehan WM, Mannelli M, Friberg P, Grebe SK, Timmers HJ, et al. 2011 Catecholamine metabolomic and secretory phenotypes in phaeochromocytoma. Endocrine-Related Cancer 18 97-111. (https:// doi.org/10.1677/ERC-10-0211)

Elston MS, Meyer-Rochow GY, Conaglen HM, Clarkson A, CliftonBligh RJ, Conaglen JV \& Gill AJ 2015 Increased SSTR2A and SSTR3 expression in succinate dehydrogenase-deficient pheochromocytomas and paragangliomas. Human Pathology 46 390-396. (https://doi.org/10.1016/j.humpath.2014.11.012)

Ghayee HK, Bhagwandin VJ, Stastny V, Click A, Ding LH, Mizrachi D, Zou YS, Chari R, Lam WL, Bachoo RM, et al. 2013 Progenitor cell line (hPheo1) derived from a human pheochromocytoma tumor. PLOS ONE 8 e65624. (https://doi.org/10.1371/journal.pone.0065624)

Giubellino A, Woldemichael GM, Sourbier C, Lizak MJ, Powers JF, Tischler AS \& Pacak K 2012 Characterization of two mouse models of metastatic pheochromocytoma using bioluminescence imaging. Cancer Letters 316 46-52. (https://doi.org/10.1016/j. canlet.2011.10.019)

Habu S, Fukui H, Shimamura K, Kasai M, Nagai Y, Okumura K \& Tamaoki N 1981 In vivo effects of anti-asialo GM1. I. Reduction of NK activity and enhancement of transplanted tumor growth in nude mice. Journal of Immunology 127 34-38.

Harari A \& Inabnet WB 3rd 2011 Malignant pheochromocytoma: a review. American Journal of Surgery 201 700-708. (https://doi. org/10.1016/j.amjsurg.2010.04.012)

Ho YP, Schnabel V, Swiersy A, Stirnnagel K \& Lindemann D 2012 A small-molecule-controlled system for efficient pseudotyping of prototype foamy virus vectors. Molecular Therapy 20 1167-1176. (https://doi.org/10.1038/mt.2012.61)

Janssen I, Blanchet EM, Adams K, Chen CC, Millo C, Herscovitch P, Taieb D, Kebebew E, Lehnert H, Fojo AT, et al. 2015 Superiority of $\left[{ }^{68} \mathrm{Ga}\right]$-DOTATATE PET/CT to other functional imaging modalities in the localization of SDHB-associated metastatic pheochromocytoma and paraganglioma. Clinical Cancer Research 21 3888-3895. (https:// doi.org/10.1158/1078-0432.CCR-14-2751)

Jemal A, Bray F, Center MM, Ferlay J, Ward E \& Forman D 2011 Global cancer statistics. CA: A Cancer Journal for Clinicians 61 69-90. (https://doi.org/10.3322/caac.20107)

Kasai M, Yoneda T, Habu S, Maruyama Y, Okumura K \& Tokunaga T 1981 In vivo effect of anti-asialo GM1 antibody on natural killer activity. Nature 291 334-335. (https://doi.org/10.1038/291334a0)

Khanna C \& Hunter K 2005 Modeling metastasis in vivo. Carcinogenesis 26 513-523. (https://doi.org/10.1093/carcin/bgh261)

Kong G, Grozinsky-Glasberg S, Hofman MS, Callahan J, Meirovitz A, Maimon O, Pattison DA, Gross DJ \& Hicks RJ 2017 Efficacy of peptide receptor radionuclide therapy for functional metastatic

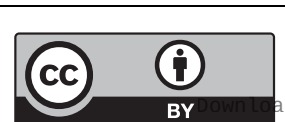

This work is licensed under a Creative Commons Attribution 4.0 International License. 
paraganglioma and pheochromocytoma. Journal of Clinical Endocrinology and Metabolism 102 3278-3287. (https://doi. org/10.1210/jc.2017-00816)

Korpershoek E, Pacak K \& Martiniova L 2012 Murine models and cell lines for the investigation of pheochromocytoma: applications for future therapies? Endocrine Pathology 23 43-54. (https://doi. org/10.1007/s12022-012-9194-y)

Labelle M \& Hynes RO 2012 The initial hours of metastasis: the importance of cooperative host-tumor cell interactions during hematogenous dissemination. Cancer Discovery 2 1091-1099. (https://doi.org/10.1158/2159-8290.CD-12-0329)

Laube M, Kniess T \& Pietzsch J 2016 Development of antioxidant COX-2 inhibitors as radioprotective agents for radiation therapy-a hypothesis-driven review. Antioxidants 5 E14. (https://doi. org/10.3390/antiox5020014)

Lenders JWM \& Eisenhofer G 2017 Update on modern management of pheochromocytoma and paraganglioma. Endocrinology and Metabolism 32 152-161. (https://doi.org/10.3803/ EnM.2017.32.2.152)

Lenders JW, Eisenhofer G, Mannelli M \& Pacak K 2005 Phaeochromocytoma. Lancet 366 665-675. (https://doi.org/10.1016/ S0140-6736(05)67139-5)

MacDougall JR, Croy BA, Chapeau C \& Clark DA 1990 Demonstration of a splenic cytotoxic effector cell in mice of genotype SCID/SCID. BG/BG. Cellular Immunology 130 106-117. (https://doi. org/10.1016/0008-8749(90)90165-N)

Martiniova L, Kotys MS, Thomasson D, Schimel D, Lai EW, Bernardo M, Merino MJ, Powers JF, Ruzicka J, Kvetnansky R, et al. 2009 Noninvasive monitoring of a murine model of metastatic pheochromocytoma: a comparison of contrast-enhanced microCT and nonenhanced MRI. Journal of Magnetic Resonance Imaging 29 685-691. (https://doi.org/10.1002/jmri.21654)

Martiniova L, Lu J, Chiang J, Bernardo M, Lonser R, Zhuang Z \& Pacak K 2011 Pharmacologic modulation of serine/threonine phosphorylation highly sensitizes PHEO in a MPC cell and mouse model to conventional chemotherapy. PLOS ONE 6 e14678. (https:// doi.org/10.1371/journal.pone.0014678)

Morgenroth A, Cartellieri M, Schmitz M, Gunes S, Weigle B, Bachmann M, Abken H, Rieber EP \& Temme A 2007 Targeting of tumor cells expressing the prostate stem cell antigen (PSCA) using genetically engineered T-cells. Prostate 67 1121-1131. (https://doi. org/10.1002/pros.20608)

Nishikado H, Mukai K, Kawano Y, Minegishi Y \& Karasuyama H 2011 NK cell-depleting anti-asialo GM1 antibody exhibits a lethal offtarget effect on basophils in vivo. Journal of Immunology $\mathbf{1 8 6}$ 5766-5771. (https://doi.org/10.4049/jimmunol.1100370)

Ohta S, Lai EW, Taniguchi S, Tischler AS, Alesci S \& Pacak K 2006 Animal models of pheochromocytoma including NIH initial experience. Annals of the New York Academy of Sciences $\mathbf{1 0 7 3}$ 300-305. (https://doi.org/10.1196/annals.1353.034)

Ohta S, Lai EW, Morris JC, Pang AL, Watanabe M, Yazawa H, Zhang R, Green JE, Chan WY, Sirajuddin P, et al. 2008 Metastasis-associated gene expression profile of liver and subcutaneous lesions derived from mouse pheochromocytoma cells. Molecular Carcinogenesis $\mathbf{4 7}$ 245-251. (https://doi.org/10.1002/mc.20388)

PDQ® Adult Treatment Editorial Board. PDQ pheochromocytoma and paraganglioma treatment. Updated 08/18/2017. (available at: https:// www.cancer.gov/types/pheochromocytoma/patient/ pheochromocytoma-treatment-pdq). Accessed on 4 April 2018.

Peitzsch M, Pelzel D, Glockner S, Prejbisz A, Fassnacht M, Beuschlein F, Januszewicz A, Siegert G \& Eisenhofer G 2013 Simultaneous liquid chromatography tandem mass spectrometric determination of urinary free metanephrines and catecholamines, with comparisons of free and deconjugated metabolites. Clinica Chimica Acta $\mathbf{4 1 8}$ 50-58. (https://doi.org/10.1016/j.cca.2012.12.031)

Powers JF, Evinger MJ, Tsokas P, Bedri S, Alroy J, Shahsavari M \& Tischler AS 2000 Pheochromocytoma cell lines from heterozygous neurofibromatosis knockout mice. Cell and Tissue Research 302 309-320. (https://doi.org/10.1007/s004410000290)

Powers JF, Korgaonkar PG, Fliedner S, Giubellino A, Pacak K, Sahagian GG \& Tischler AS 2014 Cytocidal activities of topoisomerase 1 inhibitors and 5-azacytidine against pheochromocytoma/paraganglioma cells in primary human tumor cultures and mouse cell lines. PLOS ONE 9 e87807. (https://doi. org/10.1371/journal.pone.0087807)

Salmenkivi K, Heikkila P, Haglund C \& Arola J 2004 Malignancy in pheochromocytomas. APMIS 112 551-559. (https://doi. org/10.1111/j.1600-0463.2004.apm1120901.x)

Stirnnagel K, Luftenegger D, Stange A, Swiersy A, Mullers E, Reh J, Stanke N, Grosse A, Chiantia S, Keller H, et al. 2010 Analysis of prototype foamy virus particle-host cell interaction with autofluorescent retroviral particles. Retrovirology 7 45. (https://doi. org/10.1186/1742-4690-7-45)

Tan TH, Hussein Z, Saad FF \& Shuaib IL 2015 Diagnostic performance of (68)Ga-DOTATATE PET/CT, (18)F-FDG PET/CT and (131)I-MIBG scintigraphy in mapping metastatic pheochromocytoma and paraganglioma. Nuclear Medicine and Molecular Imaging 49 143-151. (https://doi.org/10.1007/s13139-015-0331-7)

Ullrich M, Bergmann R, Peitzsch M, Cartellieri M, Qin N, EhrhartBornstein M, Block NL, Schally AV, Pietzsch J, Eisenhofer G, et al. 2014 In vivo fluorescence imaging and urinary monoamines as surrogate biomarkers of disease progression in a mouse model of pheochromocytoma. Endocrinology 155 4149-4156. (https://doi. org/10.1210/en.2014-1431)

Ullrich M, Bergmann R, Peitzsch M, Zenker EF, Cartellieri M, Bachmann M, Ehrhart-Bornstein M, Block NL, Schally AV, Eisenhofer G, et al. 2016 Multimodal somatostatin receptor theranostics using [(64)Cu]Cu-/[(177)Lu]Lu-DOTA-(Tyr(3))octreotate and AN-238 in a mouse pheochromocytoma model. Theranostics 6 650-665. (https://doi.org/10.7150/thno.14479)

Ziegler CG, Ullrich M, Schally AV, Bergmann R, Pietzsch J, Gebauer L, Gondek K, Qin N, Pacak K, Ehrhart-Bornstein M, et al. 2013 Antitumor effects of peptide analogs targeting neuropeptide hormone receptors on mouse pheochromocytoma cells. Molecular and Cellular Endocrinology 371 189-194. (https://doi.org/10.1016/j. mce.2012.12.011)

Received in final form 2 July 2018

Accepted 12 July 2018
() 2018 The authors Published by Bioscientifica Ltd. Printed in Great Britain

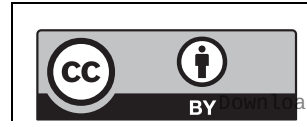

This work is licensed under a Creative Commons Attribution 4.0 International License. ded from Bioscientifica.com at $04 / 26 / 2023$ 12:46:55PM via free access 